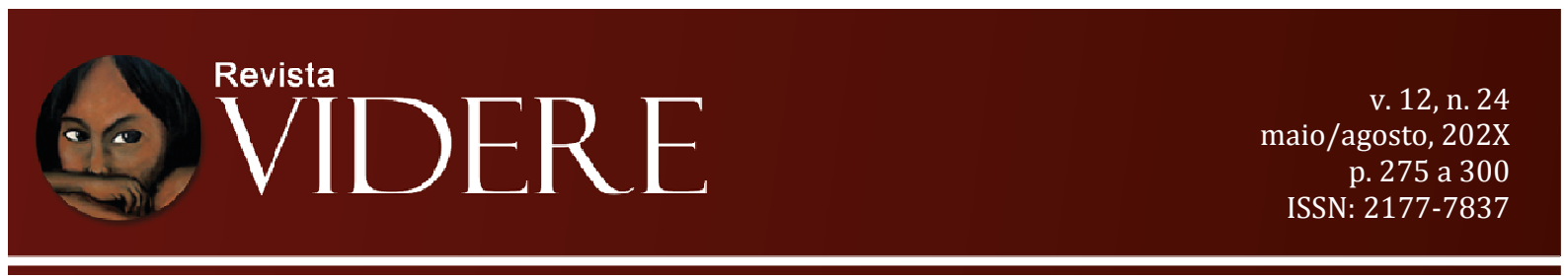

\title{
O TRABALHO INFANTIL INDÍGENA NO BRASIL: UM PARALELO ENTRE A DIVERSIDADE CULTURAL E A UNIVERSALIDADE DOS DIREITOS HUMANOS
}

\author{
INDIGENOUS CHILD LABOR IN BRAZIL: A PARALLEL BETWEEN \\ CULTURAL DIVERSITY AND THE UNIVERSALITY OF HUMAN RIGHTS
}

\author{
André Viana Custódio \\ Doutor em Direito (UFSC), Brasil. Mestre em \\ Direito (UFSC), Brasil. \\ Professor do Programa de Pós-Graduação em \\ Direito - Mestrado e Doutorado (UNISC) \\ E-mail: andreviana.sc@gmail.com \\ OrcID: https://orcid.org/0000-0002-2618-0156
}

\author{
Higor Neves de Freitas \\ Mestrando em Direito pelo Programa de \\ E-mail: freitashigor_@hotmail.com. \\ OrcID: http://orcid.org/0000-0002-1546-6538
}

RESUMO: Crianças e adolescentes indígenas são exploradas em atividades de trabalho, entretanto, essa violação de direito é sustentada, por muitas vezes, em um discurso de diversidade cultural que acaba mascarando e naturalizando essa violação de direito. $\mathrm{O}$ objetivo do trabalho é compreender o contexto do trabalho infantil indígena por meio de um paralelo entre a diversidade cultural e a universalidade dos direitos humanos. Os objetivos específicos buscam contextualizar do trabalho infantil indígena no Brasil, demonstrar a proteção jurídica contra a exploração do trabalho infantil indígena, bem como analisar um paralelo entre o discurso do relativismo cultural e a universalidade dos direitos humanos em um contexto do trabalho infantil indígena. Como problema de pesquisa, questiona-se: como se estabelece o enfrentamento do trabalho infantil indígena, levando-se em consideração a diversidade cultural e a universalidade de direitos humanos? A hipótese indica que apesar do estabelecimento de um respeito à diversidade cultural, existe uma proteção jurídica contra a exploração do trabalho infantil e de garantias fundamentais de crianças e adolescentes, não podendo, portanto, se utilizar de um discurso de relativismo cultural como uma justificação para as violações de direitos humanos. $\mathrm{O}$ método de abordagem da presente pesquisa foi o dedutivo e o método de procedimento monográfico, desenvolvendo-se o estudo por meio das técnicas de pesquisa bibliográfica e documental. Os principais resultados demonstram a necessidade de um diálogo intercultural para atingir os valores universais, entre eles, a dignidade humana e proporcionar o enfrentamento de violações de direitos de crianças e adolescentes indígenas.

PALAVRAS-CHAVE: Trabalho infantil indígena; crianças e adolescentes indígenas; políticas públicas. 


\begin{abstract}
Indigenous children and adolescents are exploited in work activities, however, this rights violation is often supported by a cultural diversity discussion that ends up masking and naturalizing it. The general goal of the work is to understand the context of indigenous child labor through a parallel between cultural diversity and the universality of human rights. The specific goals, aim to contextualize indigenous child labor in Brazil, demonstrate the legal protection against child labor exploitation, as well as to analyze a parallel between the cultural relativism discussion and the universality of human rights in the context of indigenous child labor. As a research problem, it is questioned: how should indigenous child labor be tackled, taking into account the cultural diversity and universality of human rights? The hypothesis indicates that despite the establishment of a respect for cultural diversity, there is legal protection against the exploitation of child labor and children and adolescents fundamental guarantees, therefore, cultural relativism can not be used as a justification for human rights violations. The approach method of the present research is deductive and the procedure method is monographic, the study being developed through the use of bibliographic and documental research techniques. The main results demonstrate the necessity of an intercultural dialogue in order to achieve the universal values, including human dignity and to provide means to tackle indigenous children and adolescents rights violations.
\end{abstract}

KEYWORDS: Indigenous child labor; indigenous children and adolescents; policies.

\title{
1 Introdução
}

Crianças e adolescentes são explorados em atividades de trabalhos que extrapolam os seus limites, o que resulta em consequências ao seu desenvolvimento. Muitas dessas crianças e adolescentes são indígenas, os quais realizam, muitas vezes, atividades de agricultura, artesanato, entre outras. Entretanto, apesar da existência de uma extensa proteção internacional e nacional contra a exploração do trabalho infantil, tendo em vista que se trata de uma violação de direitos humanos, um discurso mascarado pela diversidade, relativismo cultural e um e práticas de colaboração coletiva acaba perpetuando essa forma de exploração do trabalho humano, que se agrava pela ausência e fragilidade das políticas públicas de atendimento.

O objetivo do trabalho é a compreensão o contexto do trabalho infantil indígena por meio de um paralelo entre a diversidade cultural e a universalidade dos direitos humanos. Os objetivos específicos buscam contextualizar o trabalho infantil indígena no Brasil, demonstrar a proteção jurídica contra a exploração do trabalho infantil indígenas em um contexto de garantia de direitos humanos, bem analisar um paralelo entre o discurso do relativismo cultural e a universalidade dos direitos humanos em um contexto do trabalho infantil indígena. 
Como problema de pesquisa, questiona-se: como se estabelece o enfrentamento do trabalho infantil indígena, levando-se em consideração a diversidade cultural e a universalidade de direitos humanos? A hipótese indica que o discurso de relativismo cultural, por muitas vezes, acaba mascarando violações de direitos humanos de crianças e adolescentes indígenas, tendo em vista que as tarefas cotidianas são transformadas, de forma gradativa, em trabalho infantil. Assim, tendo em vista a existência de uma extensa proteção jurídica contra a exploração do trabalho infantil e de garantias fundamentais de crianças e adolescentes, não se pode utilizar o discurso do relativismo cultural como uma justificativa para violações de direitos humanos, tornando necessário o enfrentamento do trabalho infantil.

Há a necessidade de uma abordagem sobre o tema, tendo em vista que se torna necessário um aperfeiçoamento de políticas públicas para a proteção contra a exploração do trabalho infantil indígena, tendo como base um debate sobre a diversidade cultural e a universalidade dos direitos humanos. Tem-se uma importância jurídica que se ressalta em um contexto de crianças e adolescentes indígenas em situação de trabalho infantil, tendo seus direitos violados. Por fim, demonstra-se uma relevância social para a realização da pesquisa em uma necessidade se superar as condições de exclusão social no qual as crianças e adolescentes indígenas estão, por muitas vezes, inseridas, que se torna propício para a exploração, que é mascarado por um discurso pela diversidade cultural. Dessa forma, demonstra-se o valor acadêmico do presente tema, tendo em vista a necessidade de aportes teóricos para a discussão das políticas públicas contra a exploração do trabalho infantil indígena, tendo como base um paralelo entre a diversidade cultural e a universalidade dos direitos humanos.

O método de abordagem da presente pesquisa foi o dedutivo e o método de procedimento monográfico, desenvolvendo-se o estudo por meio das técnicas de pesquisa bibliográfica e documental.

Como principais resultados, se verifica que a concepção internacional de direitos humanos, por muitas vezes, já se tornou instrumento de exclusão e desigualdade, devendo ser aplicado por meio de um diálogo entre as demais culturas para atingir uma integração de valores universais e da dignidade humana, fortalecendo a proteção da criança e do adolescente indígena e afastando o discurso que naturaliza o trabalho infantil como uma forma de relativismo cultural.

\section{0 contexto do trabalho infantil indígena no Brasil}


O contexto do trabalho infantil indígena no Brasil requer uma abordagem histórica. Nessa perspectiva, relata-se muitos abusos sexuais e físicos sofridos de marujos violentos por grumetes e pajens e até mesmo as crianças acompanhadas pelos pais e as órfãs eram acompanhadas de forma cuidadosa para se manterem virgens até a chegada à Colônia. Nessa época, meninas de quinze anos eram consideradas aptas a casar e meninos de nove anos seriam capazes de realizar trabalho pesado, pois o cotidiano infantil era extremamente penoso, tendo em vista que embora não fossem ainda homens, "eram tratados como se fossem, e ao mesmo tempo eram considerados como pouco mais que animais cuja mão de obra deveria ser explorada enquanto durasse sua vida útil” (RAMOS, 2018, p. 19-48).

A cultura indígena estabelecia uma forma de participação de crianças e adolescentes em atividades cotidianas, com o objetivo de prepará-las para a vida adulta. Desde cedo, os meninos começavam a caçar animais, domesticar pássaros e tratar-lhes as feridas para, assim, começar a acompanhar os pais na caça e na pesca. Ademais, aprendem a construir canoas com uma só casca para, junto com os adultos, e "com seus pequenos remos ou com as próprias mãos e, com flechinhas, tratando de pescar ou até apanhando as mãos os peixes à vista” (ALTMAN, 2018, p. 234). Já as meninas acompanhavam suas mães nos afazeres das mulheres indígenas, quais sejam, "cuidar das plantações, colher e trazer legumes em suas canastras, cozer a mandioca, fazer a farinha, cuidar dos irmãos a quem carregam às costas numa tipoia, balançar a rede" (ALTMAN, 2018, p. 234).

Os indígenas, geralmente, praticavam uma cultura de subsistência, cujo objetivo era produzir os alimentos a fim de satisfazer as necessidades de sobrevivência, sem qualquer acúmulo de excedentes. Era cultivado mandioca, milho, batata-doce, feijão, amendoim, tabaco, abóbora, algodão, pimentas, abacaxi, mamão, erva-mate, guaraná e diversas outras plantas. Destaca-se, entretanto, que apesar de serem agricultores, este povo não constituía povoados permanentes e fixos. Pelo contrário, a mobilidade era uma de suas características, pois havia o deslocamento de tribos pelo desgaste do solo, diminuição da reserva de caça, disputas internas ou pela morte de seu chefe (COTRIM, 1999, p. 13). Outra tarefa comum era a coleta de frutas, caules, raízes de vegetais, que geralmente ocorria em tribos que não conheciam a agricultura, incluindo-se até mesmo a procura por animais minúsculos, tais como, certas larvas, determinadas espécies de formigas e gafanhotos, bem como produtos de origem animal, como ovos de tartaruga, mel, entre outros (MELATTI, 1993, p. 51).

Os homens eram incumbidos das tarefas que implicavam maior esforço físico, entre elas; um trabalho coletivo para preparação das terras para o cultivo, seja abrindo clareiras na mata e derrubando árvores com seus machados de pedra, seja limpando o terreno 
com queimadas, e para a construção das habitações; a caça e pesca com arco e flecha; as atividades mais arriscadas, como mergulho e a guerra; a produção de armas, canoas e adornos respectivos de seu sexo; a tomada de decisões em prol da comunidade e a direção dos rituais. Em geral, suas atividades eram divididas com a finalidade de prover a unidade doméstica, atos de guerra e intermediações com o sobrenatural (COUTO, 1998, p. 92).

Já as mulheres, dedicavam-se a cultivar o plantio; da coleta e da pesca com timbó; confeccionar a cestaria, cerâmica, alimentos, bebidas; bem como os adornos de seu respectivo sexo; executar todas as tarefas domésticas; carregar os mantimentos nas expedições de guerra e retirar as águas das canoas. Essas tarefas eram divididas pela especialização do trabalho dos membros do grupo feminino de acordo com a idade. Assim, a preparação do algodão e de seus derivados e a fabricação de bebidas fermentadas seriam atividades dos jovens; já o cultivo dos campos, a elaboração da farinha e o transporte de alimentos seria cargo das adultas; a confecção de objetivos de cerâmica, por fim, seriam as atividades das mais idosas do grupo (COUTO, 1998, p. 92).

Meninos e meninas costumam imitar os adultos de seu sexo, nos brinquedos,
preparando-se, assim, para o futuro. As meninas brincam com bonecas, os
meninos flecham calangos e passarinhos com a ajuda de pequenos arcos.
Mas nem tudo que as crianças fazem é brinquedo: as meninas ajudam a
tomar conta dos irmãos menores, por exemplo. Há, pois, tarefas que são
atribuídas a pessoas de determinadas idades. Por exemplo, entre os índios
Krahó, cabe aos meninos e aos velhos carregar as armas e a carne para a
aldeia, enquanto os caçadores entram na aldeia disputando uma corrida de
toras. Entre os mesmos índios cabe às crianças e aos velhos espantar os
pássaros das roças no período que precede a colheita. Entre os antigos
Tupinambá eram as moças que mastigavam as raízes com que se faziam as
bebidas (MELATTI, 1993, p. 63-64).

Após a chegada das navegações portuguesas, os europeus começaram a explorar o pau-brasil, árvore conhecida como ibirapitanga - que significa "madeira vermelha" pelos índios e abundante pelo litoral, momento no qual o rei de Portugal o declarou como monopólio da Coroa portuguesa e se proibiu a extração sem prévia permissão do governo português e o pagamento do tributo correspondente. A extração do pau-brasil dependia do trabalho dos índios para derrubar as árvores, cortá-las em toras e carregá-las até os locais do embarque dos navios. Esse trabalho ocorria de forma amigável por meio do escambo, isto é, troca de uma série de objetos, entre eles, pedaços de tecidos, espelhos, anzóis, facas, canivetes, oportunidade na qual também participavam muitas crianças e adolescentes (COTRIM, 2007, p. 195). Esse caráter predatório de extração do pau-brasil estimulou o comportamento nômade das tribos, tendo em vista que os exploradores se deslocavam pelas 
matas do litoral ao passo em que a madeira se esgotava, o que refletiu em apenas algumas feitorias em pontos da costa para proteger a madeira de ataques de tribos hostis e franceses (COTRIM, 1999, p. 195).

O relacionamento existente entre comerciantes portugueses e os povos indígenas se tornaram conflituosos à proporção que os índios resistiam a se submeter aos interesses europeus, estes que não hesitaram em impor a escravidão e usar a violência. Ainda que o governo de Portugal defendesse a liberdade dos indígenas, os colonos recorriam à guerra justa, que seria o confronto contra os indígenas, autorizada pelo governo português e seus representantes, o qual era justificada nos casos de indígenas que se recusassem à conversão à fé cristã imposta pelos portugueses ou impedir a sua divulgação, bem como por quebrar acordos ou agir com hostilidade contra os colonizadores, estabelecendo inúmeros confrontos nas regiões litorâneas de europeus contra os indígenas tupinambás, caetés, carijós, tupiniquins, tabajaras, guaranis e potiguares (COTRIM, 1999, p. 198).

Nesse passo, a mão-de-obra indígena passava a ser alienada das sociedades tribais por meio do uso da força militar e expedições de guerra contra índios inimigos da fé cristã ou pelas tropas de regaste. O resgate seria o ato de comprar ou trocar produtos de origem portuguesas por aqueles índios que eram prisioneiros de outras tribos e teriam sidos condenados a serem comidos e sacrificados por seus rivais. Contudo, o que parecia ser um legítimo ato de benevolência cristã para salvar vidas, não passava de um artificio para burlar a legislação e condenar os indígenas a escravidão (GOMES, 2002, p. 111). Ressalte-se que não existia uma nação indígena, mas sim grupos diversos e que estavam muitas vezes em conflito, fato que permitiu aos portugueses encontrar em diversas oportunidades aliados entre os próprios indígenas até mesmo na luta contra outros grupos que resistiam a eles, o que não indica que os índios não tenham resistido fortemente à invasão portuguesa, sobretudo, quando se tratou de sua escravização (FAUSTO, 2000, p. 40).

Além disso, o ensino de um ofício para as crianças indígenas também se tornou uma preocupação dos jesuítas, que "entendiam o trabalho como condição de dignidade, ou ainda, o caminho para a própria salvação" (CUSTÓDIO; VERONESE, 2009, p. 21), o que demonstra que estas missões jesuítas "não apenas contavam com o trabalho de adultos, mas também de crianças em variados serviços, principalmente quando ultrapassada a idade dos sete anos" (CUSTÓDIO; VERONESE, 2009, p. 21). O ensino jesuítico estabeleceu também experiências diferenciadas, pois passou a estabelecer o castigo como processo pedagógico, “o que para os índios causava estranheza, uma vez que não conheciam a prática de bater em crianças" (CUSTÓDIO; VERONESE, 2009, p. 21), mas por outro lado, trouxe também 
manifestações positivas, como o canto, exercício da imaginação e uma nova ritualísticas (CUSTÓDIO; VERONESE, 2009, p. 21).

O período colonial foi responsável pelas primeiras iniciativas de caráter assistencial no Brasil, oportunidade na qual as congregações religiosas se instalaram, tais como, as Santa Casas de Misericórdia, que passaram a atender "enjeitados, escravos, estrangeiros e expostos sem qualquer tipo de diferença de sexo, condição ou idade" (CUSTÓDIO; VERONESE, 2009, p. 21). Durante o século XVIII até o século XIX, a Roda dos Expostos vislumbrava livrar as crianças "recém-nascidas da situação de abandono e ampará-las em instituições de caridade" (LIMA; VERONESE, 2012, p. 18), consistindo em um recipiente para depositar o bebê e que proporcionava anonimato à pessoa que abandonava este. Desse modo, considerando o valor insignificante que as crianças negras e indígenas desempenhavam na época de escravidão, muitas eram doadas pelos senhores de escravos a estas instituições (LIMA; VERONESE, 2012, p. 18-19).

Ressalte-se que a escravidão indígena se consolidou de maneira mais significativa a partir de meados do século XVI, momento no qual os colonos passaram a necessitar de mão-de-obra para a produção de açúcar. Em vista disso, os índios aprisionados durante confrontos contra portugueses e alguns aliados passaram a ser distribuídos ou vendidos como escravos (COTRIM, 2007, p. 198). As principais atividades econômicas do Brasil colônia, seja na mineração, seja na agricultura, passaram a ser desenvolvidas com a mão-de-obra de crianças filhas de escravos e indígenas que passaram a ser exploradas de forma exaustiva nas lavouras de tabaco, cana-de-açúcar e milho e, ademais, serviam também como empregados domésticos ou vendedores ambulantes (NASCIMENTO; COSTA, 2015, p. 134).

A mão-de-obra indígena era reposta através de expedições armadas contra tribos, conhecidas como entradas, as quais eram sancionadas pela administração colonial e bandeiras, quando organizadas por particulares. Com a experiência adquirida na caça aos indígenas, muitos destes bandeirantes se colocavam a serviços dos governos-gerais do Brasil para não só exterminar a presença de indígenas de determinadas regiões, como ainda para obter novos escravos (GOMES, 2002, p. 142). Todavia, a cultura indígena era incompatível com tal trabalho intenso, regular e compulsório pretendido pelos europeus. Assim, apesar de não serem preguiçosos, tampouco vadios, eram acostumados a fazer apenas o necessário para garantir a sua subsistência, sem qualquer noção de "trabalho contínuo ou do que chamaríamos hoje de produtividade" (FAUSTO, 2000, p. 49), aspectos que eram totalmente estranhos a eles. 
No final do século XIX, durante o processo de revolução industrial, a mão de obra infantil passou a ser utilizada na indústria, tendo em vista que eram consideradas uma mão de obra barata e de fácil adaptabilidade, o que causava não apenas acidentes de trabalho, como ainda doenças ocupacionais (CUSTÓDIO; MOREIRA, 2018, p. 182-183). É pertinente destacar que "a presença de crianças e adolescentes no trabalho industrial, tornou-se, talvez, o referencial mais importante de que a pobreza não deixará de rondar as famílias de muitos" (GOMES, 2002, p. 262) e que, de tão precária, "dependia em parte do trabalho dos próprios filhos"(GOMES, 2002, p. 263), os quais sofriam muitos acidentes de trabalho, resultado dos "maus-tratos que patrões e representantes dos cargos de chefia" (GOMES, 2002, p. 263) infligiam nos jovens trabalhadores.

O processo chamado de "colonização" que demonstra a exploração na América Latina resultou em um genocídio de diversas e centenas de culturas a partir de um sistema social de opressão sobre a comunidade indígena. Isso porque houve um extermínio sistemático, que se solidifica com a diminuição da população indígena, na época de 1500 , de cerca de 6 milhões, para apenas cerca menos de 1 milhão atualmente (COTRIM, 1999, p. 1516). A população indígena, em 2010, era composta por cerca de 896.9 mil, o que compreende $0,47 \%$ da população brasileira, os quais $36,2 \%$ residem na área urbana e 63,8\% na área rural. A região Norte é responsável pela maior parte da população indígena, o que abrange 342.8 mil habitantes, enquanto a Região Sul possui apenas 78.7 mil (INSTITUTO BRASILEIRO DE GEOGRAFIA E ESTATÍSTICA, 2010).

Em 2010, havia mais de 3.4 milhões de crianças e adolescentes em situação de trabalho, o que representa 3,9\% das 86.4 milhões de pessoas ocupadas. Desses, $61 \%$ eram do sexo masculino e 39\% do sexo feminino (INSTITUTO BRASILEIRO DE GEOGRAFIA E ESTÁTISTICA, 2010). 


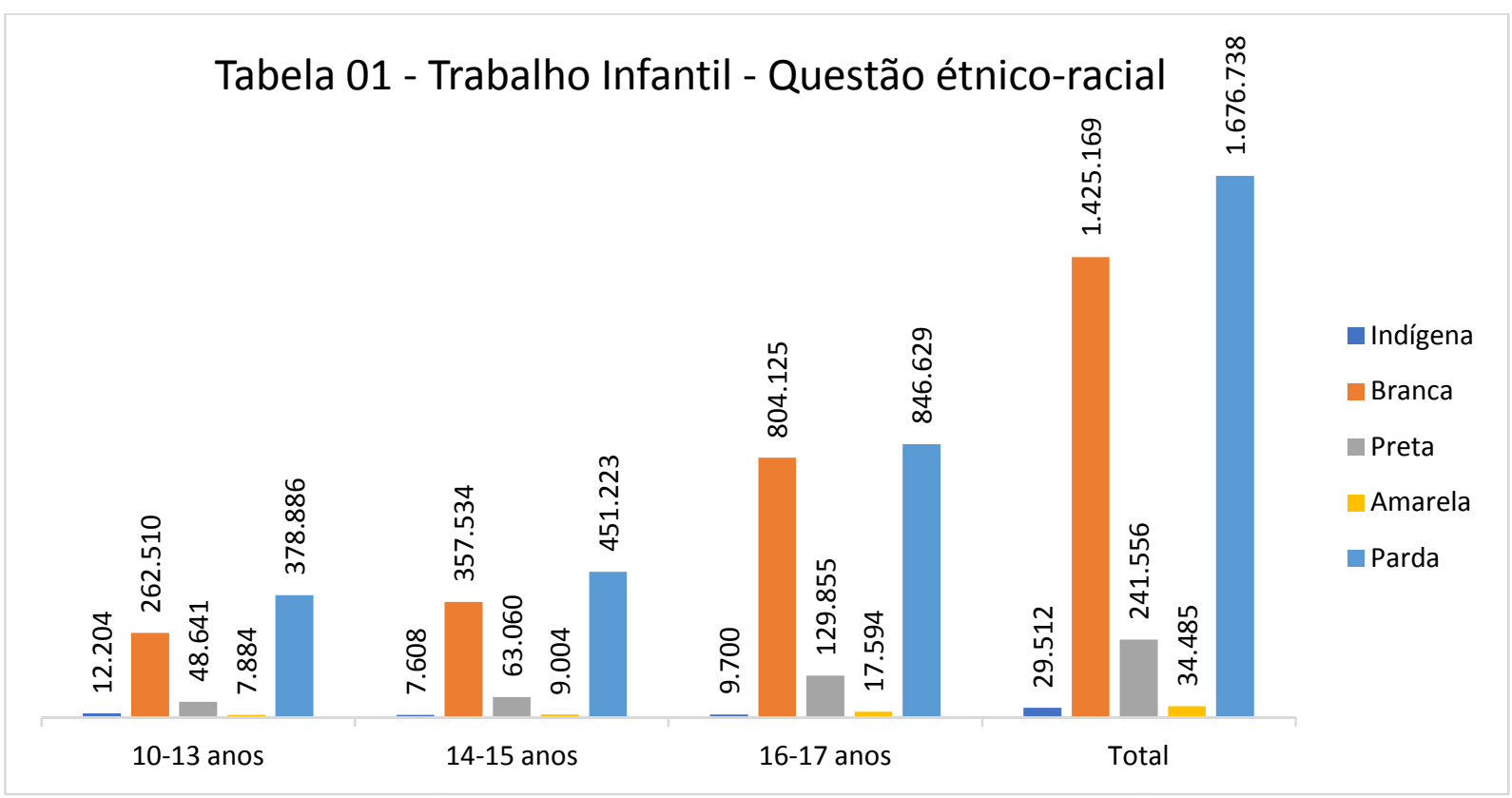

Fonte: IBGE, Censo 2010.

Em uma análise étnico-racial, considerando crianças e adolescentes entre 10 e 17 anos, apesar dos negros, que abrange os pretos e pardos, possuírem uma maior expressividade percentual, há mais de 29 mil crianças e adolescentes indígenas exploradas pelo trabalho infantil, o que significa $0,56 \%$ do total dessas crianças e a dos adolescentes explorados. Esse é um número significativo, tendo em vista que a população indígena compõe apenas $0,47 \%$ da população brasileira, demonstrando uma considerável presença de trabalho infantil indígena no cenário nacional (INSTITUTO BRASILEIRO DE GEOGRAFIA E ESTÁTISTICA, 2010).

A questão social abrange determinados elementos que demonstram a problemática geral e que propõe o entendimento da situação da criança e adolescente indígena. Isso porque muitas trabalham com o transporte de pessoas em canoas, venda e confecção de artesanatos e até mesmos em atividades insalubres e perigosas. Em uma análise histórica, verifica-se que a cultura indígena sedimentou que as crianças e adolescentes devem aprender e colaborar com a comunidade desde cedo, seja na própria agricultura ou ainda em artesanatos. Entretanto, gradativamente as tarefas cotidianas foram substituídas pelo trabalho infantil e um discurso mascarado de diversidade cultural que objetiva a naturalização dessa condição de exploração do trabalho das crianças e adolescentes indígenas.

Existem constantes violações de direitos fundamentais de crianças e adolescentes e isso requer um discernimento quanto à forma de vida indígena, suas organizações sociais e culturais, que são diferentes das concepções capitalistas e eurocêntricas. Assim, torna-se 
importante não confundir tais exploração com o aprendizado indígena (SILVA, 2018, p. 138). Ainda que tenha o estabelecimento de uma consciência protetiva, se observa "que as crianças indígenas continuam a trabalhar como uma forma de interagir com o grupo em que estão inseridas e como modo de agregar maior renda aos seus grupos familiares para suprir as necessidades existentes" (MARDERS; REIS, 2016, p. 227). Portanto, a discussão sobre as políticas públicas que envolvem o trabalho infantil indígena encontra resistência na conceituação, tendo em vista as diversas especificidades existentes sobre o tema, quais sejam:

[...] o pequeno percentual da população indígena em relação à população nacional; consulta e participação das organizações indígenas representativas; a maior parte da população indígena vive no meio rural, tornando mais difícil caracterizar o trabalho infantil; dificuldade de definição do que seja trabalho infantil indígena, pois o que pode ser considerado como tal para o não indígenas pode não ser para o indígena, visto que partilham cosmovisões diferenciadas; faltas de programas específicos envolvendo as crianças indígenas; a sobreposição de normas, pois, ao mesmo tempo, Brasil é signatário de convenções da Organização Internacional do Trabalho (OIT) que abordam o direito das crianças e de outras, que tratam do direito dos povos indígenas (NASCIMENTO; COSTA, 2019, p. 200-201).

Dessa forma, compreende-se que a cultura indígena propõe uma participação de crianças e adolescentes em atividades quotidianas, com o objetivo de caráter pedagógico e interação social, que acabam, por muitas vezes, se tornando atividades de trabalho, trazendo consequências ao desenvolvimento social e humano de crianças e adolescentes, tornando necessário o seu enfrentamento.

\section{Os direitos humanos e a proteção jurídica contra a exploração do trabalho infantil indígena}

O reconhecimento internacional dos direitos humanos foi fortalecido no processo de reconstrução a partir do pós-guerra, como resposta aos horrores e atrocidades cometidos durante o regime nazista na Alemanha, considerando que a $2^{\mathrm{a}}$ Guerra Mundial significou em uma ruptura com os direitos humanos, e se constituiu, assim, fruto de um recente movimento de internacionalização de direitos (PIOVESAN, 2004, p. 46-47). Estes passaram a expressar as condições mínimas para uma vida digna, reconhecidos através da história de diversos povos e são encarados como "imprescindíveis para que a vida humana tenha a dignidade que lhe é inerente" (GORCZEVSKI, 2016, p. 25). 
Os direitos humanos passaram a ser compreendidos como a base da sociedade a partir de um consenso filosófico, político e de direito e com a incorporação de direitos humanos em diversas constituições. Desse modo, os direitos humanos seriam o núcleo de justiça, tendo em vista que "toda violação a direitos humanos é injusta, ainda que nem toda injustiça seja uma violação de direitos humanos" (ALEXY, 2014, p. 174), positivando os direitos do ser humano e tornando-se fundamental para a compreensão básica dos direitos fundamentais e da jurisdição constitucional, sendo definidos por cinco características, quais sejam, a sua universalidade, seu caráter fundamental, a sua abstração, o seu caráter moral e a sua prioridade (ALEXY, 2014, p. 173-179). Esse processo de universalização permitiu a formação de um abstrato teórico capaz de formar um sistema internacional de proteção, o qual é integrado por tratados internacionais que refletem uma "consciência ética contemporânea compartilhadas pelos Estados" (PIOVESAN, 2006, p. 13), momento no qual passam a invocar um consenso internacional acerca de temas centrais a fim de estabelecer parâmetros mínimos protetivos.

A Constituição da República Federativa do Brasil de 1988 incorporou ao ordenamento jurídico nacional a teoria da proteção integral, que garantiu uma proteção especial à criança e ao adolescente em condição peculiar de pessoa em desenvolvimento por meio da tríplice responsabilidade compartilhada entre a família, a sociedade e o Estado:

Art. 227. É dever da família, da sociedade e do Estado assegurar à criança, ao adolescente e ao jovem, com absoluta prioridade, o direito à vida, à saúde, à alimentação, à educação, ao lazer, à profissionalização, à cultura, à dignidade, ao respeito, à liberdade e à convivência familiar e comunitária, além de colocá-los a salvo de toda forma de negligência, discriminação, exploração, violência, crueldade e opressão (BRASIL, 1988).

Portanto, ordenamento jurídico consolidou uma tríplice responsabilidade para a família, a sociedade e para o Estado para a proteção dos direitos da criança e do adolescente, o que desenvolve uma conjuctura de uma atuação articulada desses na efetivação dos direitos fundamentais da criança e do adolescente e com uma participação ativa na construção das políticas públicas na área da infância. Além disso, o Estatuto da Criança e do Adolescente, Lei 8.069, de 13 de julho de 1990, passou a regulamentar a proteção jurídica da criança e do adolescente, a partir do estabelecimento de uma prioridade absoluta na efetivação de direitos:

Art. $4^{\circ}$ É dever da família, da comunidade, da sociedade em geral e do poder público assegurar, com absoluta prioridade, a efetivação dos direitos referentes à vida, à saúde, à alimentação, à educação, ao esporte, ao lazer, à 
profissionalização, à cultura, à dignidade, ao respeito, à liberdade e à convivência familiar e comunitária.

Parágrafo único. A garantia de prioridade compreende:

a) primazia de receber proteção e socorro em quaisquer circunstâncias;

b) precedência de atendimento nos serviços públicos ou de relevância pública;

c) preferência na formulação e na execução das políticas sociais públicas;

d) destinação privilegiada de recursos públicos nas áreas relacionadas com a proteção à infância e à juventude (BRASIL, 1990).

Nesse contexto, passou a se construir uma proteção jurídica estabelecida por meio de um reconhecimento da dignidade humana desde a infância, definida em diversos tratados e convenções internacionais sobre direitos humanos, entre eles, a Convenção Internacional dos Direitos das Crianças, ratificada pelo Brasil em 24 de setembro de 1990, por meio do Decreto n. 99.710, de 21 de novembro de 1990 (ORGANIZAÇÃO DAS NAÇÕES UNIDAS, 1989), o Pacto de São José da Costa Rica, ratificada em 25 de setembro de 1992, por meio do Decreto n. 678, de 6 de novembro de 1992 (CONVENÇÃO AMERICANA SOBRE DIREITOS HUMANOS, 1969) e a Declaração Universal dos Direitos Humanos, ratificada em 27 de março de 1968 (ORGANIZAÇÃO DAS NAÇÕES UNIDAS, 1948), as quais estabeleceram o Direito da Criança e do Adolescente como ramo jurídico, oportunidade na qual se passou a reconhecer crianças e adolescentes como sujeitos de direitos, o que culminou em um reordenamento nas políticas públicas no Brasil.

Além disso, a Constituição Federal, atualizada pela Emenda Constitucional n. 20, de 15 de dezembro de 1998, vedou a realização do trabalho perigoso, insalubre ou noturno a pessoas com idade abaixo de 18 anos, bem como qualquer forma de trabalho abaixo de 16 anos, ressalvado a condição de aprendiz a partir dos 14 anos (BRASIL, 1988). Nessa linha de raciocínio, o Estatuto da Criança e do Adolescente, regulamentou a proteção contra a exploração do trabalho infantil ao estabelecer limites especiais para o trabalho antes dos 18 anos de idade:

Art. 67. Ao adolescente empregado, aprendiz, em regime familiar de trabalho, aluno de escola técnica, assistido em entidade governamental ou não-governamental, é vedado trabalho:

I - noturno, realizado entre as vinte e duas horas de um dia e as cinco horas do dia seguinte;

II - perigoso, insalubre ou penoso;

III - realizado em locais prejudiciais à sua formação e ao seu desenvolvimento físico, psíquico, moral e social;

IV - realizado em horários e locais que não permitam a frequência à escola (BRASIL, 1990). 
No mesmo sentido, a Organização Internacional do Trabalho promulgou duas normativas internacionais, quais sejam, a Convenção $n^{\circ} 138$, ratificada pelo Brasil em 28 de junho de 2001, por meio do Decreto n. 4.134, de 15 de fevereiro de 2002 (ORGANIZAÇÃO INTERNACIONAL DO TRABALHO, 1973) e a Convenção $\mathrm{n}^{\circ} 182$, ratificada em 2 de fevereiro de 2000, por meio do Decreto n. 3.597, de 12 de setembro de 2000 (ORGANIZAÇÃO INTERNACIONAL DO TRABALHO, 1999), bem como as Recomendação $n^{\circ} 146$ (ORGANIZAÇÃO INTERNACIONAL DO TRABALHO, 1973) e Recomendação nº 190 (ORGANIZAÇÃO INTERNACIONAL DO TRABALHO, 1999) com a finalidade de adotar uma política nacional de erradicação do trabalho infantil, elevação progressiva dos limites da idade mínima para o trabalho, bem como ações imediatas para erradicar o trabalho infantil.

Assim, se desenvolve políticas públicas em diversos níveis, entre eles, de atendimento, de proteção, de justiça e de promoção de direitos que se desenvolvem nos municípios e se materializam por meio de uma atuação intersetorial dos órgãos que compõem o Sistema de Garantia de Direitos, o que garante a proteção dos direitos fundamentais da criança e do adolescente, inclusive contra o trabalho infantil, e da dignidade humana (SOUZA; SERAFIM, 2019, p. 94).

Convém, entretanto, destacar que a Constituição Federal de 1988 previu, também, uma proteção especial a cultura indígena, no artigo 231, no qual reconhece que um respeito às suas crenças, tradições, línguas, costumes, bem como sua organização social:

Art. 231. São reconhecidos aos índios sua organização social, costumes, línguas, crenças e tradições, e os direitos originários sobre as terras que tradicionalmente ocupam, competindo à União demarcá-las, proteger e fazer respeitar todos os seus bens (BRASIL, 1988).

$\mathrm{O}$ artigo 215, parágrafo $1^{\circ}$, do texto constitucional, garantiu também um respeito "as manifestações das culturas populares, indígenas e afro-brasileiras, e das de outros grupos participantes do processo civilizatório nacional" (BRASIL, 1988). O texto constitucional, portanto, reconheceu os sistemas próprios de organização política, social e jurídica com a finalidade de garantir uma continuidade cultural e étnica, o que reconhece todos os sistemas de valores, conhecimentos e organização social do povo indígena. Os povos indígenas são reconhecidos como organizações sociopolíticas e socioculturais autônomas e as políticas públicas governamentais devem garantir a continuidade cultural por meio de uma perpetuação de valores para as gerações futuras e presentes. A relação de autonomia busca que as comunidades vivam de forma livre, pois o longo processo de invasão do Brasil, a partir de 
1500, resultou no enfraquecimento das tradicionais formas de organizações políticas e sociais, o que impactou na organização interna da vida dos indígenas (BANIWA, 2015, p. 117-122).

A avalanche de denúncias sobre a corrupção, irregularidades administrativas, gestão fraudulenta do patrimônio indígena, principalmente quanto aos recursos naturais fortaleceram a necessidade da criação de um órgão capaz de centralizar a prestação de serviços aos povos indígenas, surgindo a Fundação Nacional do Índio (FUNAI) e a elaboração de uma legislação especial para os indígenas (ARAÚJO, 2006, p. 31). Assim, o Estatuto do Índio, Lei 6.001, de 19 de dezembro de 1973, veio estabelecer uma forma de controle sobre a população indígena (BRASIL, 1973). A concepção não é muito diferente da existente na época da invasão portuguesa, tendo em vista que o Estatuto do Índio objetiva justamente a integração dos índios com a sociedade brasileira de forma progressiva e harmoniosa, tornando necessária surja novas legislações sobre o tema, apesar de que apesar do esforço por parte das organizações indígenas e da sociedade civil na tentativa de garantir a aprovação de uma nova legislação, não houve nenhum empenho do Governo na aprovação (ARAÚJO, 2006, p. 31; 45-46).

A Convenção $\mathrm{n}^{\circ} 169$ da Organização Internacional do Trabalho, ratificada em 25 de julho de 2002, por meio do Decreto n. 5.051, de 19 de abril de 2004, aborda sobre Povos Indígenas e Tribais e passa a garantir não só uma proteção cultural, mas uma perspectiva de gozo de direitos humanos e liberdades fundamentais a estes (ORGANIZAÇÃO INTERNACIONAL DO TRABALHO, 2004). Essa convenção foi o primeiro instrumento internacional que tratou dignamente os direitos coletivos dos povos indígenas, pois estabeleceu padrões mínimos e afastou o princípio da aculturação e da assimilação quanto ao respeito desses povos. Entra as medidas, desenvolveu-se uma perspectiva de se decidir de acordo com suas prioridades, tanto na formulação, quanto na implementação e avaliação dos planos e programas do governo que os afetam (ARAÚJO, 2006, p. 59).

A Declaração das Nações Unidas Sobre os Direitos dos Povos Indígenas, aprovada pela Organização das Nações Unidas no dia 7 de setembro de 2007 também abordou sobre o respeito a identidade cultural, direitos humanos e às liberdades fundamentais e os protegem contra o trabalho infantil (ORGANIZAÇÃO DAS NAÇÕES UNIDAS, 2007). Já a Declaração Universal sobre a Diversidade Cultural, apesar de garantir o respeito às diferenças advindas de outras culturas, afirma que a diversidade cultural estaria inseparável da dignidade humana, pois "ninguém pode invocar a diversidade cultural para violar os direitos humanos garantidos pelo direito internacional, nem para limitar seu alcance" (ORGANIZAÇÃO DAS NAÇÕES UNIDAS, 2001). No mesmo sentido, a Convenção sobre a Proteção e Promoção da 
Diversidade das Expressões Culturais, da Organização das Nações Unidas, ratificada em 16 de janeiro de 2007, por meio do Decreto n. 6.177, de $1^{\circ}$ de agosto de 2007, garante a diversidade cultural e um respeito por todas as culturais, contudo, em seu artigo $2^{\circ}$, aborda sobre o respeito aos direitos humanos e às liberdades fundamentais afirmando que:

\begin{abstract}
A diversidade cultural somente poderá ser protegida e promovida se estiverem garantidos os direitos humanos e as liberdades fundamentais, tais como a liberdade de expressão, informação e comunicação, bem como a possibilidade dos indivíduos de escolherem expressões culturais. Ninguém poderá invocar as disposições da presente Convenção para atentar contra os direitos do homem e as liberdades fundamentais consagrados na Declaração Universal dos Direitos Humanos e garantidos pelo direito internacional, ou para limitar o âmbito de sua aplicação (ORGANIZAÇÃO DAS NAÇÕES UNIDAS, 2007, www.ibermuseus.org).
\end{abstract}

Dessa forma, se verifica que apesar da existência de um contexto de multiculturalidade e interculturalidade e respeito às diversidades culturais existente entre os diversos povos, não se pode usar tal motivo como uma justificativa para a violação de direitos humanos, como por exemplo, o trabalho infantil indígena. Assim, verifica-se a extensa proteção jurídica contra a exploração do trabalho infantil indígena, envolvendo não só a legislação nacional, como ainda tratados e convenções internacionais, o que culmina em uma discussão acerca da aplicação da universalização dos direitos humanos e do alcance dessa normatividade, considerando o contexto da diversidade cultural, para efetivar as políticas públicas contra a exploração do trabalho infantil.

\title{
4 Um paralelo entre a diversidade cultural e direitos humanos e fundamentais no contexto do trabalho infantil indígena
}

A herança histórica de exploração das comunidades indígenas é um dos grandes obstáculos para o enfrentamento ao trabalho infantil. O tradicional envolvimento de crianças e adolescentes nas tarefas cotidianas transformou-se, por conta do processo de expansão do modo de produção capitalista, em formas precárias de exploração do trabalho humano em diversas modalidades, incluindo o trabalho infantil. Mascarado pelo discurso da diversidade, do relativismo cultural e das práticas de colaboração coletiva, crianças e adolescentes indígenas são submetidas as diversas formas de exploração agravadas pela ausência e fragilidade das políticas públicas de atendimento. 
Destaca-se que diversas culturas possuem diferentes concepções, valores, costumes, visões de mundo, que acabam sendo questionados por outras formas de cultura, o que torna a conceituação de direitos humanos uma abstração intelectual de um determinado momento histórico e de um específico conteúdo cultural, fato que gera um debate acerca do alcance das normas de direitos humanos (GORCZEVSKI, 2016, p. 30). Nesse contexto, após decorridos mais de 500 anos da exploração do Brasil, se passou a discutir situações que atingem crianças e adolescentes indígenas quanto "aos direitos humanos e fundamentais à vida, à cultura, à saúde e à educação" (NASCIMENTO; COSTA, 2015, p. 137), e, principalmente, acerca da exploração da mão-de-obra das crianças e adolescentes indígenas, as quais perduraram durante o período de "colonização" e se perpetuam no século XXI, momento no qual as sociedades indígenas se mantém em uma vulnerabilidade social (NASCIMENTO; COSTA, 2015, p. 137)

$\mathrm{Na}$ história da humanidade sempre existiu agrupamentos humanos com formas complexas capaz de os diferenciar, o que coloca a cultura como esse modo de se manifestar na humanidade na sociedade, nas nações, nos povos (SANTOS, 2006, p. 8). A cultura é resultado de um processo acumulativo, pois resulta de toda experiência histórica das demais gerações. Este processo envolve as mais diversas manifestações, incluindo até os bens de consumo e as normas capazes de gerir os diferentes grupos sociais, como seus costumes e crenças. Assim, se desenvolve aspectos espirituais, materiais e humanos (DE SOUZA, 2016, p. 148).

As diversas tradições culturais múltiplas presentes entre os grupos sociais representariam a prova de que seria impossível o estabelecimento de normas universais de comportamento social e, nesse passo, uma simples leitura antropológica dos direitos humanos não conseguiria privilegiar uma "evidência empírica" para "a possível existência de valores humanos universais, pois essas encontram-se cobertas pelas diferentes manifestações culturais" (BARRETTO, 2004, p. 287).

O multiculturalismo emancipatório garante o reconhecimento das diferenças culturais, tendo em vista que se trata de um "valor aberto e democrático, que representa distinções, diversidade e heterogeneidade" (WOLKMER, 2006, p. 119) e demonstram "um horizonte culturalmente compartilhado e dialógico" (WOLKMER, 2006, p. 119). A transmissão uma ideia de um Brasil pluriétnico, contudo, se torna necessário o exercício dessa concepção na vida prática da sociedade nacional, pois apenas tal convivência entre as culturas garante a possibilidade de garantir uma espécie de coexistência lógica de etnia e cidadania. Assim, os indígenas valorizam não apenas os instrumentos de garantia de direitos, tais como 
"possuir documentos civis e ter acesso a políticas públicas, mas principalmente como instrumento de acesso a direitos estratégicos, como participação e representação política que os habilitem a influenciar as tomadas de decisões de seus interesses" (BONIWA, p. 120).

La interculturalidad, em cambio, aún no existe. Es algo por construir. Va mucho más ala del respeto, la tolerância y el reconocimiento de la diversidade; señala y alienta, más bien, um processo y um proyecto social, político, epistémico y ético, dirigido a la construcción de sociedades, relaciones y condiciones de vida nuevas y que tiene que ver com la cosmología y la vida em general, incluyendo los conocimientos y saberes, la memoria ancestral y la relación com la madre natureza y la espiritualidade, entre otras. Estos son partes del problema de las relaciones y condiciones históricas y actuales de dominacion, exclusión, desigualdad e inequidade, como también de la conflictividad que estas relaciones y condiciones engrendran - y las lógicas y racionalidades que forman parte de ellas -, e s decir la colonialidad com sus cuatro ejes o potestades ya señalados (WALSH, 2008, p. 164).

Essas concepções devem ser empregadas como formas de traçar uma política de diversidade cultural. Entretanto, a interculturalidade "demanda mais do que respeito; somente estará consolidada, do modo como pensamos, quando, para além do respeito, os grupos oprimidos puderem exercer de fato a autonomia para o uso, da maneira que lhes parecer melhor, dos instrumentos para se fazerem respeitar" (PERUZZO, 2006, p. 23). A interculturalidade e o diálogo dos sistemas "es un campo en debate y construcción, desde el cual se cuestionan la racionalidad que se promueve como universal desde las ciencias de occidente, y se lucha por propuestas pluralistas para la generación y la aplicación de los conocimientos" (RUIZ; VILLAMAR, 2011, www.scielo.br). O interculturalismo como orientador de políticas culturais traz propostas e reinvidicações das comunidades e movimentos indígenas como uma luta contínua de colonização e descolonização, pois permite um ajuste das realidades em consonância com os elementos culturais por meio de um processo de interação (MARTIN et al., 2015). Essa forma de respeito da diversidade cultural busca impedir uma evaporação natural de culturas e civilizações "autênticas" pelo projeto baseado na hegemonia no poder da civilização ocidental:

O contraste entre a hegemonia política e econômica da civilização ocidental e a resistência cultural de outras entidades civilizacionais produz uma psicologia exclusivista, através do uso do conceito de nativos, como uma categoria absoluta para o definir outros. Mas muitos não têm tal olhar; e sua perspectiva é ilustrada por meio da utilização da palavra inglesa "natives" e de seus equivalentes em outras línguas ocidentais. Quando nós ocidentais, chamamos os povos de "nativos", estamos implicitamente retirando o tom 
cultural de nossa percepção a seu respeito, vendo-os como animais selvagens que infestam o país onde encontramos, como parte da fauna e flora locais e não como homens, com paixões semelhantes às nossas. Enquanto os considerarmos como "nativos", poderemos exterminá-los ou, como é mais provável hoje em dia, domesticá-los e, honestamente (talvez não de todo equivocados) acreditar que estamos melhorando a raça, mas não começaremos a compreendê-los (DAVUTOGLU, 2004, p. 106-107).

A concepção universal dos direitos humanos demarcada pela sofre resistência dos adeptos do relativismo cultural, surgindo um amplo debate sobre o alcance das normas de direitos humanos. Na concepção relativista, esse movimento internacional de direitos humanos passaria a flexibilizar as noções de jurisdição e soberania nacional, pois seria responsável por consagrar um parâmetro relativo à proteção dos direitos humanos. Dessa forma, cada cultura possui o seu discurso acerca dos direitos fundamentais, que está intrinsecamente relacionado às circunstâncias culturais e históricas da sociedade e ao sistema econômico, cultural, político, social e moral vigente em determinado grupo social (PUREZA, 2004, p. 58-59).

A abordagem acerca da questão da legitimidade universal dos direitos humanos deixou de ser abstrata e teórica e passou a fazer parte de um conjunto de fatores decisivos para a sua eficácia. Assim, "a razão nuclear para que se considere o problema dos fundamentos dos direitos humanos no mesmo patamar de importância analítica da sua positividade" seria o "fato de que a eficácia dos direitos humanos se encontra ligada à sua fundamentação" (BARRETTO, 2004, p. 282).

É pertinente registrar que ao passo no qual há um processo de aperfeiçoamento dos mecanismos de proteção dos direitos humanos, seja no plano internacional, seja no plano nacional, há um aumento significativo "de casos de violações de direitos, tanto em quantidade, quanto em novas modalidades" como nunca visto na história (PRONER, 2002, p. 37). Para tanto, os sistemas regionais asseguram a existência de um aumento na efetividade dos direitos humanos, mesmo que em jurisdição limitadas, considerando que evitam que ocorram transgressões quando o Estado não cumpre o seu dever de garantir a proteção e de tomar medidas para punir os responsáveis (CARDOSO, 2012, p. 37).

Nesse passo, a polêmica dos direitos humanos, no mundo contemporâneo, solidifica-se em um paralelo entre duas visões, as quais são debatidas na concepção do enfrentamento do trabalho infantil indígena e que, para muitos, são a justificativa para legitimar muitas violações de direitos humanos, tendo em vista que há uma visão abstrata, baseada na concepção ocidental do direito e no valor da identidade e, por outro lado, uma 
visão localista "e centrada na ideia particular de cultura e de valor da diferença. Cada uma dessas visões dos direitos propõe um determinado tipo de racionalidade e uma maneira de como colocá-los em prática" (FLORES, 2002, p. 13).

A primeira linha argumentativa se baseia em uma proclamação da existência de valores da dignidade da pessoa humana, os quais seriam válidos em todo mundo e que constituiriam um núcleo de resistência a todo absolutismo, a partir de uma origem iluminista das declarações revolucionárias do século XVIII. Já a segunda nega toda a possibilidade de fundamentação universal dos direitos humanos, pois a manifestação do estado nacional de direito seria o único instrumento para a sua positivação com base na autodeterminação dos povos (BARRETTO, 2004, p. 283).

A construção de um argumento do mínimo universal passa por um reconhecimento de que seria possível o estabelecimento de características comuns de seres humanos, os quais serviriam de fundamento para consolidar uma sociedade em laços de solidariedade (BARRETTO, 2004, p. 284). Nesse contexto, de um ponto de vista cultural, cada forma de vida possui "uma legítima e integral pretensão de conseguir a verdade e, por ela, a universalidade", ao passo de que "todas as sociedades tendem a aproximar-se e aglomerar-se" e, assim, passam a ter uma "tendência também à assimilação e à socialização" (RUBIO, 2010, p. 94).

Se os direitos humanos não existissem, isso contaria como um forte argumento a favor de formas fortes de relativismo cultural. Do mesmo modo, a existência dos direitos humanos contaria como uma boa razão contra as formas fortes de relativismo cultural. Se os direitos humanos existem, existe então uma base comum do direito que, como decorre do conceito de uma base, poderia muito bem ser compatível em um âmbito considerável com a diversidade cultural. Uma base comum parece, nesse sentido, ser indispensável para uma ordem jurídica global, qualquer que seja seu tipo. Tudo isso mostra que a questão da existência dos direitos humanos possui um significado teórico e prático real (ALEXY, 2014, p.177).

Torna-se, importante, a integração de valores universais no contexto da sociedade multicultural, momento no qual se identifica valores morais universais que são identificados em todas as sociedades, entre eles, a identidade humana, o valor humano, a dignidade humana, a igualdade, bem como a promoção do bem-estar, devendo-se intermediar estes valores morais em sociedades multiculturais, sem que estes percam o seu caráter de universalidade. Esses valores devem ser considerados universais, pois respondem a "exigência de todos os seres humanos, independente de cultura, nacionalidade ou religião" 
(GOMES, 2002, p. 300) e são considerados "valores em virtude de serem cultivados de serem cultivados em todas as sociedades" (GOMES, 2002, p. 300).

$\mathrm{O}$ conceito de direitos humanos se fundamenta em direitos dotados por uma natureza universal e uma suposição de que os indivíduos têm uma dignidade humana absoluta e irredutível (PRONER, 2002, p. 22). A dignidade humana expressa uma qualidade intrínseca dos seres humanos, independentemente de sua conduta ou ainda de seu status, ou seja, não é concedida por ninguém, tampouco pode ser retirada pelo Estado ou pela sociedade, em nenhuma situação e "jamais será perdida pelo seu titular" (SARMENTO, 2016, p. 104). Essas características permitem "avaliar a possível natureza universal dos direitos humanos e suas relações com as diferentes realidades culturais. Trata-se, portanto, de explicitar os valores morais que se encontram na base de todas as culturas" (GOMES, 2002, p. 299) e, nesse sentido, encontrar "o ponto de equilíbrio racional entre valores universais e diversidade cultural" (GOMES, 2002, p. 299).

\begin{abstract}
Trata-se de um debate intrinsecamente falso, cujos conceitos polares são igualmente prejudiciais para uma concepção emancipatória de direitos humanos. Todas as culturas são relativas, mas o relativismo cultural enquanto atitude filosófica é incorrecto. Todas as culturas aspiram a preocupações e valores universais, mas o universalismo cultural, enquanto atitude filosófica, é incorrecto. Contra o universalismo, há que propor diálogos interculturais sobre preocupações isomórficas. Contra o relativismo, há que desenvolver critérios políticos para distinguir política progressista de política conservadora, capacitação de desarme, emancipação de regulação (SANTOS, 1997, www.scielo.br).
\end{abstract}

Assim, apesar do ambiente cultural indígena ser totalmente diverso da cultura ocidental, deve-se atingir um espectro ideal de dignidade humana, resultante de uma concepção do ser humano como um ser dotado de diferentes capacidades naturais, mas com a possibilidade do estabelecimento de critérios comuns, que seriam importantes para a concretização dos direitos humanos em uma sociedade multicultural (BARRETTO, 2004, p. 298). Necessita-se de um diálogo entre as perspectivas diversas, entre o passado e o presente, tendo em vista que o encontro cultural engloba os demais, incluindo os aspectos culturais, valores e modos de organização diversos (SANTOS, 1997, www.scielo.br). Os direitos humanos se referem a uma categoria capaz de proteger a existência das diferentes capacidades inerentes ao ser humano. Assim, apesar de na cultura indígena se viver em um ambiente distinto, culturalizado e com um meio social que tende a dominá-los, deve-se garantir uma proteção diferenciada a estes (BALDI, 2004, p. 36). 
Contudo, o relativismo cultural jamais poderá ser o argumento de justificação de graves casos de violação de direitos humanos a fim de ficar imunes ao controle da comunidade internacional, tendo em vista que ao optar pela ratificação de instrumentos internacionais de proteção dos direitos humanos, os Estados consentiram em respeitar tais regras, não podendo, portanto, se isentar do cumprimento de suas obrigações internacionais (PIOVESAN, 2004, p. 62). Essa concepção internacional de direitos humanos se torna importante, considerando que os direitos fundamentais já se tornaram instrumentos para a exclusão e desigualdade com seres humanos que não se mantiveram em suas condições de titularidade, tornando importante a definição de seu nível de alcance (RUBIO, 2010, p. 32).

Ainda que exista um cenário com diversidades culturais, deve-se atentar que os direitos humanos por meio de seus diversos tratados e convenções protegem as crianças e adolescentes contra a exploração do trabalho infantil e funcionam como uma restrição ao relativismo cultural no cenário internacional. Com efeito, não se pode admitir que diferenças advindas de outras culturas autorizem meios discriminatórios de "proteção à essas crianças ou qualquer outro indígena que labore fora de seu grupo" (MARDERS; REIS, 2016, p.230).

Assim, não se pode sustentar um discurso de autonomia do sistema jurídico e de direitos dos indígenas como forma de autorizar a violação dos direitos humanos, tendo em vista a prevalência da dignidade humana e da condição peculiar de pessoa em desenvolvimento das crianças e adolescentes indígenas, tornando-se necessária a efetivação de políticas públicas de prevenção e erradicação do trabalho infantil indígena.

\section{Considerações finais}

O contexto histórico demonstra uma relação de exploração e precariedade histórica desde o início do processo de invasão do Brasil. Apesar das crianças e adolescentes se envolverem nas atividades quotidianas da aldeia, essa relação se modificou durante os anos, tendo em vista que muitas dessas passaram a ser exploradas tanto na escravidão, quanto no trabalho infantil, em conta do processo de expansão do modo de produção capitalista. Essa forma de exploração dos indígenas se fortaleceu mascarada por um discurso de diversidade, relativismo cultural e de práticas de colaboração coletiva, bem como até mesmo pela fragilidade e ausência das políticas públicas de atendimento, atingindo muitas crianças e adolescentes.

Assim, os direitos humanos foram reconstruídos após o período pós-guerra, se constituindo como um movimento de internacionalização de direitos humanos, os quais passaram a expressar as condições mínimas e a dignidade humana, o que introduziu uma 
concepção contemporânea de direitos humanos. Nesse contexto, a Constituição Federal de 1988 incorporou a teoria da proteção integral ao ordenamento jurídico, estabelecendo a condição de sujeitos de direitos às crianças e adolescentes e uma tríplice responsabilidade compartilhada entre a família, a sociedade e o Estado. O Estatuto da Criança e do Adolescente regulamentou tal proteção por meio de uma prioridade absoluta na efetivação de direitos. Ademais, diversos tratados internacionais, entre eles, a Declaração Universal dos Direitos Humanos, a Convenção Internacional dos Direitos das Crianças, o Pacto de São José da Costa Rica, bem como as Convenções $n^{\circ}$ 138, 169 e 182 da Organização Internacional do Trabalho e, também, a Declaração das Nações Unidas sobre os Direitos dos Povos Indígenas, a Declaração Universal sobre a Diversidade Cultural, Convenção sobre a Proteção e Promoção da Diversidade das Expressões Culturais.

Portanto, apesar de um discurso cultural que objetiva a naturalização da condição de exploração do trabalho infantil indígena. Apesar das culturas possuírem concepções, valores, costumes diversos e o discurso do relativismo cultura buscar impedir uma evaporação natural das culturas e hegemonia no poder da civilização ocidental. Contudo, há uma construção lógica de um mínimo universal de reconhecimento e de características comuns dos seres humanos, que possibilitaria uma integração de valores universais, entre eles, a dignidade humana, que seria absoluta e irredutível. Desse modo, apesar do ambiente cultural indígena ser diverso da cultura ocidental, deve-se atingir um espectro ideal de dignidade humana, tendo em vista que a diversidade cultural jamais deve ser argumento para justificar a violação de direitos humanos. Essa concepção internacional se torna importante, tendo em vista que os direitos humanos já se tornaram, por muitas vezes, instrumento de exclusão e desigualdade, tornando-se importante a proteção contra a exploração do trabalho infantil indígena, com a finalidade de garantir a proteção integral e da dignidade humana de crianças e adolescentes por meio de um diálogo entre as culturas existentes.

\section{Referências}

ALEXY, Robert. Princípios Formais e outros aspectos da Teoria Discursiva do Direito. Rio de Janeiro: Forense Universitária, 2014.

ALTMAN, Raquel Zumbano. Brincando na história. In: PRIORE; Mary Del. História das crianças no Brasil. São Paulo: Contexto, 2018.

ARAÚJO, Ana Valéria. Povos indígenas e a Lei dos" Brancos": o direito à diferença. Ministério da Educação, 2006. 
BALDI, César Augusto. As múltiplas faces do sofrimento humanos: os direitos humanos em uma perspectiva multicultural. In: BALDI, César Augusto Baldi. Direitos Humanos na sociedade cosmopolita. Rio de Janeiro: Renovar, 2004.

BANIWA, Gersem. Autonomia Indígena no Brasil: desafios e possibilidades. In: DUPRAT, Débora. Convenção 169 da OIT e os Estados Nacionais. Brasília: ESMPU, 2015.

BARRETTO, Vicente de Paulo. Multiculturalismo e direitos humanos: um conflito insolúvel? In: BALDI, César Augusto. Direitos Humanos na sociedade cosmopolita. Rio de Janeiro: Renovar, 2004.

BRASIL. Constituição da República Federativa do Brasil. 1988. Disponível em: <http://www.planalto.gov.br/ccivil_03/constituicao/constitui\%C3\%A7ao.htm> Acesso em: 10 fev. 2020.

BRASIL. Estatuto da Criança e do Adolescente. 1990. Disponível em: <http://www.planalto.gov.br/ccivil_03/leis/18069compilado.htm> Acesso em: 10 fev. 2020.

BRASIL. Estatuto do Índio. 1973. Disponível em: <http://www.planalto.gov.br/ccivil_03/Leis/L6001.htm> Acesso em: 10 fev. 2020.

CARDOSO, Tatiana de Almeida Freitas R. Direitos humanos: da sua evolução à sua (in) efetividade. Revista Videre, v. 4, n. 8, p. 30-40, 2012.

COTRIM, Gilberto. História do Brasil. 1 ed. São Paulo: Saraiva, 1999.

COTRIM, Gilberto. História Global: Brasil e geral. 8 ed. São Paulo: Saraiva, 2007.

COUTO, Jorge. A construção do Brasil: Lisboa: Arco-Íris, 1998.

CUSTÓDIO, André Viana; VEROSENE; Josiane Rose Petry. Crianças esquecidas: o trabalho infantil doméstico no Brasil. Curitiba: Multidéia, 2009.

DAVUTOGLU, Ahmet. Cultura global versus pluralismo cultural: hegemonia civilizacional ou diálogo e interação entre civilizações In: BALDI, César Augusto. Direitos Humanos na sociedade cosmopolita. Rio de Janeiro: Renovar, 2004.

DE SOUZA, Pedro Bastos. Identidade e diversidade cultural como direitos fundamentais: relação de instrumentalidade e perspectivas no contexto internacional. Revista Videre, v. 8, n. 15, p. 141-161, 2016.

FAUSTO, Boris. História do Brasil. São Paulo: Edusp, 2000.

FLORES, Joaquin Herrera. Direitos humanos, interculturalidade e racionalidade de resistência. Sequência UFSC, Florianópolis, v. 23 n. 44, p. 9-29. 2002.

GOMES, Mércio Pereira. O índio na História: o povo Tenetehara em busca da liberdade. Petrópolis: Vozes, 2002. 
GORCZEVKSI, Clóvis. Direitos Humanos, Educação e Cidadania: conhecer, educar, praticar. 2 ed. Santa Cruz do Sul: EDUNISC, 2016.

INSTITUTO BRASILEIRO DE GEOGRAFIA E ESTATÍSTICA. Censo Demográfico 2010. Rio de Janeiro: IBGE, 2010.

LIMA, Fernanda da Silva; VERONESE, Josiane Rose Petry. Os Direitos da Criança e do Adolescente: a necessária efetivação dos direitos fundamentais. Florianópolis: Fundação Boiteux, 2012.

MARDERS, Fernanda; REIS, Suzéte da Silva. O trabalho infantil indígena sancionado pela diversidade cultural. Revista da Faculdade de Direito da UFRGS, Porto Alegre, n. 34, p. 218-237, ago. 2016.

MARTIN, Nuria Belloso; RODRIGUES, Saulo Tarso; BOTELHO, Tiago Resende. Los derechos indígenas en el nuevo constitucionalismo latinoamericano: tiempo de derechos. Revista Amazônia Legal de Estudos Sócio-Jurídico-Ambientais (UFMT), v. 6, p. 1, 2015.

MELATTI, Julio Cezar. Índios do Brasil. São Paulo: HUCITEC, 1993.

MOREIRA, Rafael Bueno da Rosa; CUSTÓDIO, André Viana. A influência do direito internacional no processo de erradicação do trabalho infantil. Revista direitos fundamentais \& democracia (UniBrasil), v. 23, p. 178, 2018.

NASCIMENTO, Edmilson Alves do; COSTA, Renilda Aparecida. Indígenas crianças: uma fronteira simbólica na política de erradicação do trabalho infantil. Argumenta Journal Law, n. 31, p. 171-208, 2019.

NASCIMENTO, Edmilson Alves do; COSTA, Renilda Aparecida. Indígenas e trabalho infantil: da fronteira étnico-cultural à perspectiva de uma ação institucional diferenciada no Brasil. Argumenta Journal Law, Jacarezinho - PR, Brasil, n. 23. p. 129-158. 2015.

ORGANIZAÇÃO DAS NAÇÕES UNIDAS. Convenção sobre a Proteção e Promoção da Diversidade das Expressões Culturais. 2001. Disponível em $<$ http://www.ibermuseus.org/wp-content/uploads/2014/07/convencao-sobre-a-diversidadedas-expressoes-culturais-unesco-2005.pdf> Acesso em: 10 fev. 2020.

ORGANIZAÇÃO DAS NAÇÕES UNIDAS. Convenção sobre os Direitos das Crianças. 1989. Disponível em <http://www.planalto.gov.br/ccivil_03/decreto/19901994/D99710.htm>. Acesso em: 10 fev. 2020.

ORGANIZAÇÃO DAS NAÇÕES UNIDAS. Declaração das Nações Unidas Sobre os Direitos dos Povos Indígenas. 2007. Disponível em <https://www.un.org/esa/socdev/unpfii/documents/DRIPS_pt.pdf〉. Acesso em: 10 fev. 2020.

ORGANIZAÇÃO DAS NAÇÕES UNIDAS. Declaração Universal dos Direitos Humanos. 1948. Disponível em <https://www.ohchr.org/EN/UDHR/Documents/UDHR_Translations/por.pdf>. Acesso em: 10 fev. 2020. 
ORGANIZAÇÃO DAS NAÇÕES UNIDAS. Declaração Universal sobre a Diversidade Cultural. 2001. Disponível em <http://www.unesco.org/new/fileadmin/MULTIMEDIA/HQ/CLT/diversity/pdf/declaration_c ultural_diversity_pt.pdf> Acesso em: 10 fev. 2020.

ORGANIZAÇÃO INTERNACIONAL DO TRABALHO. Convenção 138 sobre a idade mínima de admissão ao emprego. 1973. Disponível em:

<http://white.oit.org.pe/ipec/pagina.php?seccion=47\&pagina=156> Acesso em: 10 fev. 2020.

ORGANIZAÇÃO INTERNACIONAL DO TRABALHO. Convenção 169 sobre Povos

Indígenas e Tribais. 2004. Disponível em <http://www.planalto.gov.br/ccivil_03/_ato20042006/2004/decreto/d5051.htm>. Acesso em: 10 fev. 2020.

ORGANIZAÇÃO INTERNACIONAL DO TRABALHO. Convenção 182 sobre a proibição das piores formas de trabalho infantil e ação imediata para sua eliminação. 1999.

Disponível em: <http://www.ilo.org/public/spanish/standards/relm/ilc/ilc87/com-chic.htm> Acesso em: 10 fev. 2020.

PÉREZ RUIZ, Maya Lorena; ARGUETA VILLAMAR, Arturo. Saberes indígenas y diálogo intercultural. Cultura y representaciones sociales, v. 5, n. 10, p. 31-56, 2011.

PERUZZO, Pedro Pulzatto. Direitos Humanos, povos indígenas e interculturalidade. Revista Videre, v. 8, n. 15, p. 4-18, 2016.

PIOVESAN, Flávia. A universalidade e a indivisibilidade dos direitos humanos: desafios e perspectivas. In: BALDI, César Augusto. Direitos Humanos na sociedade cosmopolita. Rio de Janeiro: Renovar, 2004.

PIOVESAN, Flávia. Direitos Humanos e Justiça Internacional. São Paulo: Saraiva, 2006.

PRONER, Carol. Os direitos humanos e seus paradoxos: análise do sistema americano de proteção. Porto Alegre: Fabris, 2002.

PUREZA, José Manuel. Direito internacional e comunidade de pessoas: da indiferença aos direitos humanos. In: BALDI, César Augusto. Direitos Humanos na sociedade cosmopolita. Rio de Janeiro: Renovar, 2004.

RAMOS, Fábio Pestana. A história trágico-marítima das crianças nas embarcações portuguesas do século XVI. In: PRIORE; Mary Del. História das crianças no Brasil. São Paulo: Contexto, 2018.

RUBIO, David Sánchez. Fazendo e desfazendo direitos humanos. Santa Cruz do Sul: EDUNISC, 2010.

SANTOS, Boaventura de Souza. Uma concepção multicultural de direitos humanos. Revista Lua Nova, v. 39, 1997.

SANTOS, José Luiz dos. O que é cultura. São Paulo: Brasiliense, 2006. 
SARMENTO, Daniel. Dignidade da pessoa humana: conteúdo, trajetórias e metodologia. Belo Horizonte: Fórum, 2016.

SILVA, Heloísa Helena Corrêa da. Proteção social e questão social dos indígenas urbanos em cidades transfronteiriças do Alto Solimões. In: HORBATH, Jorge E. Horbath; GRACIA, María Amalia. La cuestión indígena en las ciudades de las Américas. Buenos Aires: Imprenta Dorrego, 2018.

SOUZA; Ismael Francisco de; SERAFIM; Renata Nápoli Vieira. As recomendações do comitê para os direitos da criança, da convenção das nações unidas sobre os direitos da criança (1989). Santa Cruz do Sul, RS: Essere nel Mondo, 2019.

WALSH, Catherine. Interculturalidad y colonialidad del poder. Un pensamiento y posicionamiento "otro" desde la diferencia colonial. El giro decolonial. Reflexiones para una diversidad epistémica más allá del capitalismo global, p. 47-62, 2007.

WOLKMER, Antonio Carlos. Pluralismo jurídico, direitos humanos e interculturalidade. Seqüência: Estudos Jurídicos e Políticos, v. 27, n. 53, p. 113-128, 2006. 